\title{
The Deepwater Horizon Oil Spill Coast Guard Cohort study
}

\author{
Jennifer Rusiecki, ${ }^{1}$ Melannie Alexander, ${ }^{1}$ Erica G Schwartz, ${ }^{2}$ Li Wang, ${ }^{1}$ Laura Weems, ${ }^{3}$ \\ John Barrett, ${ }^{1}$ Kate Christenbury, ${ }^{4}$ David Johndrow, ${ }^{4,5}$ Renée H Funk, ${ }^{6}$ \\ Lawrence S Engel ${ }^{7}$
}

- Additional material is published online only. To view please visit the journal online (http://dx.doi.org/10.1136/ oemed-2017-104343).

${ }^{1}$ Department of Preventive Medicine and Biostatistics, F Edward Hebert School of Medicine, Uniformed Services University, Bethesda, USA ${ }^{2}$ Coast Guard, Directorate of Health, Safety and Work Life, Washington, USA

${ }^{3}$ United States Army Corps of Engineers, Safety and Occupational Health Office, Little Rock, USA

${ }^{4}$ Social \& Scientific Systems, Durham, USA

${ }^{5}$ RTI International, Research Triangle Park, Durham, USA ${ }^{6}$ Centers for Disease Control and Prevention, National Institute for Occupational Safety and Health, Atlanta, USA ${ }^{7}$ Department of Epidemiology, Gillings School of Global Public Health, University of North Carolina, Chapel Hill, USA

\section{Correspondence to}

Dr Jennifer Rusiecki, Department of Preventive Medicine and Biostatistics, F Edward Hebert School of Medicine, Uniformed Services University, Jones Bridge Rd, Bethesda, Maryland 20814, USA

jennifer.rusiecki@usuhs.edu

Received 2 February 2017

Revised 8 June 2017

Accepted 22 June 2017

Published Online First

12 September 2017

\section{Linked}

- http://dx.doi.org/10.1136/ oemed-2017-104687

Check for updates

To cite: Rusiecki J,

Alexander M, Schwartz EG,

et al. Occup Environ Med

2018:75:165-175

\section{ABSTRACT \\ Objectives Long-term studies of oil spill responders} are urgently needed as oil spills continue to occur. To this end, we established the prospective Deepwater Horizon (DWH) Oil Spill Coast Guard Cohort study.

Methods DWH oil spill responders $(n=8696)$ and non-responders ( $n=44823$ ) who were members of the US Coast Guard (20 April-17 December 2010) were included. This cohort uses both prospective, objective health data from military medical encounters and crosssectional survey data. Here, we describe the cohort, present adjusted prevalence ratios (PRs) estimating cross-sectional associations between crude oil exposure (none, low/medium, high) and acute physical symptoms, and present adjusted relative risks (RRs) based on longitudinal medical encounter data (2010-2012) for responders/non-responders and responders exposed/not exposed to crude oil.

Results Responders and non-responders in this large cohort ( $n=53519$ ) have similar characteristics. Crude oil exposure was reported by $>50 \%$ of responders. We found statistically significant associations for crude oil exposure with coughing $\left(\mathrm{PR}_{\text {high }}=1.78\right)$, shortness of breath $\left(\mathrm{PR}_{\text {high }}=2.30\right)$, wheezing $\left(\mathrm{PR}_{\text {high }}=2.32\right)$, headaches $\left(P R_{\text {high }}=1.46\right)$, light-headedness/dizziness $\left(P R_{\text {high }}=1.96\right)$, skin rash/itching $\left(\mathrm{PR}_{\text {high }}=1.87\right)$, diarrhoea $\left(\mathrm{PR}_{\text {high }}^{\text {high }}=1.76\right)$, stomach pain ( $\left.P R_{\text {high }}=1.67\right)$, nausea/vomiting $\left(P R_{\text {high }}=1.48\right)$ and painful/burning urination $\left(P R_{\text {high }}=2.89\right)$ during deployment. Longitudinal analyses revealed that responders had elevated RRs for dermal conditions ( $R R=1.09)$, as did oil-exposed responders for chronic respiratory conditions ( $R R=1.32)$, asthma $(R R=1.83)$ and dermal conditions ( $R R=1.21$ ).

Conclusions We found positive associations between crude oil exposure and various acute physical symptoms among responders, as well as longer term health effects. This cohort is well positioned to evaluate both short-term and long-term effects of oil spill exposures using both self-reported and clinical health data.

\section{INTRODUCTION}

Little is known about the health effects from oil spills on response workers, despite the frequency of these events worldwide. The Deepwater Horizon (DWH) disaster, which released approximately 200 million gallons of crude oil into the Gulf of Mexico starting 20 April 2010, was the largest marine oil spill in US history. ${ }^{1,2}$ The sea-floor oil gusher released crude oil into the marine environment for 87 days before the wellhead was capped.

\section{What this paper adds}

- Prior studies of adverse health associated with exposure to oil spills among response/clean-up workers and in communities have focused mainly on acute physical and mental health symptoms and relied primarily on relatively crude measures of oil exposure, for example, responder versus non-responder status, duration of oil spill response work, and living near versus far from the oil spill.

- Given the relative frequency and magnitude of oil spills worldwide, and oil drilling taking place in increasingly hostile environments (eg, deep on the ocean floor), where disasters are more likely, it is crucial to understand how these types of disasters affect human health, in both the short and the long term.

- The prospective Deepwater Horizon Oil Spill Coast Guard Cohort study is well positioned to answer important questions about shortterm and long-term health effects from oil spill exposures.

- Here, we report positive associations between crude oil exposure and acute symptoms not previously or rarely reported in the literature (gastrointestinal, genitourinary), as well as those reported in prior studies (respiratory, neurological and dermal symptoms); health outcomes evaluated via medical encounter over a 2-year follow-up period showed positive associations for oil exposure and incidence of respiratory and dermal outcomes.

- This insight will help inform disaster planners in implementing intervention protocols to mitigate possible adverse health effects in future events.

The unprecedented interagency response, led by the US Coast Guard, involved nearly 9000 Coast Guard workers, who carried out a wide range of response/clean-up activities.

Crude oil exposure has been the major focus of most epidemiological studies of oil spill responders/ clean-up workers and was a key safety concern in the clean-up of the DWH spill. The National Institute for Occupational Safety and Health (NIOSH) identified key exposures and hazards for the DWH responders as respiratory exposure to components of crude oil, including benzene and other volatile organic compounds, oil mist and polycyclic 
aromatic hydrocarbons, in addition to dermal exposure to crude oil. ${ }^{3}$ There is also potential for human toxicity from particulate matter generated by flaring of oil and gas at the wellhead and in situ burning of oil on the ocean's surface. ${ }^{45}$ The most commonly reported acute physical symptoms and conditions among responders and residents of regions affected by major oil spills have been respiratory symptoms, ${ }^{6-16}$ migraine headaches, ${ }^{14}$ non-migraine headaches, ${ }^{6-8} 111^{15}{ }^{17-19}$ eye irritation, ${ }^{7} 8111517-19$ throat irritation, ${ }^{8111517-19}$ nausea $^{811141520}$ and dizziness. $^{811} 15$ Conditions such as dermatitis and skin irritations have also been reported, ${ }^{7} 1421$ particularly among people who did not wear dermal protection. ${ }^{21}$ Information on long-term health effects associated with exposure to crude oil among responders/oil spill clean-up workers, $791022-25$ as well as on biological responses in humans, such as genotoxicity, endocrine alterations and oxidative stress, ${ }^{22-25}$ is very limited. A few prior studies, particularly those in the wake of the Prestige oil spill off the coast of Galicia, Spain in 2002, have investigated biomarkers of longer term effects, including measures of genotoxicity and endocrine alterations, among oil spill-exposed populations. For example, among exposed workers, significantly higher DNA damage and cytogenetic damage were found, ${ }^{26-28}$ as well as alterations in hormonal status. ${ }^{28} 29$

Other key hazards identified by the NIOSH included psychological stress, high temperatures and opportunity for injuries (ie, sprains, strains and lacerations). ${ }^{3}$ Studies focused on psychological outcomes in the wake of major oil spills worldwide have reported elevated rates of post-traumatic stress disorder and depressive symptoms. ${ }^{16-18}$ 30-33 Elevated risk for injuries from response work has also been reported, such as lower back/ lumbar pain ${ }^{7141519}$ and skin lesions. ${ }^{34}$ These have been found to be associated with more intense clean-up activities, longer duration and less use of personal protective equipment (PPE). ${ }^{15}$ Other specific exposures of concern to DWH responders were the chemical dispersants widely used in the response, Corexit 9500 and $9527 \mathrm{~A}$ - over 1.8 million gallons of these oil dispersants were applied to the surface and subsurface environments. ${ }^{35}$ Potential health effects, based on animal studies and case reports, include dermatitis, chemical pneumonitis, central nervous system depression, nausea, vomiting, injury to red blood cells, kidney or liver, respiratory irritation, and eye irritation. ${ }^{3637}$ The effects of exposure to these dispersants and their combination with crude oil on health in human populations, however, are understudied.

Given the frequent large-scale environmental contamination from oil spills and the number of people involved with the clean-up and/or who are potentially exposed to the related toxicants, these events are of great public health concern. This, coupled with the relative paucity of data on human health effects, underscores the need for follow-up studies to further address both the acute and long-term health effects of these environmental disasters. We established a cohort study among Coast Guard personnel involved in the DWH oil spill response and non-responders to investigate potential acute and longterm health effects from oil spill response work exposures. Both prospective and cross-sectional data are available for this study population. The hazards this study will address go beyond those potentially associated with exposure to crude oil, and extend to others identified by the NIOSH. ${ }^{3}$ Here, we describe the overall cohort and present results from initial cross-sectional and prospective analyses of health effects associated with response work and crude oil exposures.

\section{METHODS}

\section{Study population}

The DWH Oil Spill Coast Guard Cohort study comprised DWH oil spill responders $(n=8696)$ and non-responders $(n=44823)$ who were either on Coast Guard active duty or in the Selected Reserve between the start of the oil spill on 20 April 2010 and the end of the transition phase of the oil spill response, as defined by the Coast Guard, on 17 December $2010 .^{2}$ Responders were identified via Coast Guard administrative databases as personnel involved in some capacity in the oil spill response for at least 1 day up through 17 December 2010. Non-responders, also identified via Coast Guard administrative databases, were all active-duty and Selected Reserve Coast Guard members at any time between 20 April and 17 December 2010, for whom there was no evidence of DWH oil spill response involvement.

There are two components to this study: prospective and cross-sectional. The prospective component uses objective health data from ongoing medical encounters and health assessments conducted by the military in an equal access healthcare system, the Military Health System, as described in more detail below. The cross-sectional component uses survey data provided by a large proportion of responders on completion of their oil spill response deployment and represents acute health effects, as described below.

This study was approved by the Institutional Review Boards (IRB) of the Uniformed Services University, the US Coast Guard and the University of North Carolina, Chapel Hill. The Centers for Disease Control and Prevention (CDC) IRB determined that the CDC coauthor's role was not research.

\section{Prospective follow-up and medical data}

For all active-duty cohort members, medical encounter data are available for this study dating back to October 2007 from care sought from within the Military Health System, an equal access healthcare system. These data are available via the Military Health System Data Repository and include International Classification of Diseases, 9th Revision (ICD-9) codes for each health encounter from both inpatient and outpatient direct care obtained at a military treatment facility, and purchased inpatient and outpatient care obtained outside a military treatment facility. Additionally, pharmacy, laboratory and radiology data are available. We currently have these data through 31 December 2015 and plan to include data from additional years as they become available. For approximately one-quarter $(23.8 \%)$ of the Selected Reservists in our study, medical data from their annual Periodic Health Assessment are available, dating back to January 2009. These data include vital signs blood pressure; lab results and body mass index; smoking status; self-reported health/pain concerns, medication use, mental health issues, substance abuse and unresolved operational/deployment health issues; audiogram data; vision test results; and cardiovascular screening.

\section{Cross-sectional data: surveys}

Two computer-based exit surveys were administered to Coast Guard responders after their DWH response deployment(s). The first survey, 'survey 1', launched on 25 June 2010, was superseded by a more detailed survey, 'survey 2,' launched on 1 November 2010. Many of the factors assessed were similar between the two surveys, but while survey 1 assessed exposures and health effects on an ever/never scale, survey 2 ascertained them semiquantitatively. Similar surveys were used for Coast Guard responders following the Hurricane Katrina response. ${ }^{38} 39$ Responders who completed survey $1(\mathrm{n}=3657)$ 
were asked to complete survey 2 when it became available, and 78\% $(\mathrm{n}=2847)$ did so. All Coast Guard personnel still responding to the DWH oil spill as of 1 November 2010 were asked to complete only survey $2(\mathrm{n}=2008)$. Both surveys queried responders about deployment-related duration and timing, location, general tasks ('missions'), exposures to crude oil/oily water (hereafter, referred to simply as 'crude oil'), oil dispersants, combustion engine exhaust, PPE use, acute symptoms experienced and lifestyle factors. These brief surveys were designed to be completed within $15-20 \mathrm{~min}$ in order to increase participation.

\section{Exposure assessment}

For prospective comparisons of participating in oil spill response work, we can compare responders with non-responders. Additionally, for all responders, we have data on duration and timing of deployment, as well as their general category of responder work (eg, worked on a cutter or boat, aviator, Strike Team member, other), for use in prospective analyses to compare various groups of responders with non-responders or with other responders.

For responders who completed an exit survey, we additionally have data on deployment-related exposures to crude oil, oil dispersants, other chemicals, location of deployment, missions performed during deployment and PPE use. While survey 1 assessed exposure to crude oil via inhalation, ingestion, skin contact and submersion on an ever/never scale, survey 2 assessed frequency of exposure via these routes using a 5-point Likert scale: never, rarely, sometimes, most of the time and all of the time. Exposures to oil dispersant and exhaust fumes were assessed on the same Likert scale.

\section{Health outcomes assessment}

In addition to longitudinal medical data from the Military Health System Data Repository and Periodic Health Assessments, we have cross-sectional health data from responders who completed an exit survey. Both surveys queried responders about acute health effects/symptoms (hereafter referred to as 'acute symptoms') experienced during deployment, including sunburn, behavioural health, musculoskeletal stress, injuries and insomnia. Additionally, survey 2 elicited acute symptoms on a three-level scale (never, sometimes, most of the time) for general symptoms/acute irritants, respiratory, neurological, dermatological, gastrointestinal, genitourinary, ear/nose/throat and cardiovascular symptoms. Survey 1 additionally elicited information specifically on heat stress-related symptoms.

\section{Serum biomarkers}

The Department of Defense Serum Repository (DoDSR) houses over 50 million serum samples collected since 1985 from members of the US Armed Forces, including the Coast Guard. It receives approximately 2 million new serum specimens per year as a result of mandatory military HIV screening programmes. ${ }^{40}$ Active-duty members and some Selected Reserve members in the cohort have existing serial serum samples housed at the DoDSR. These are available for measurement of markers of exposure, such as albumin adducts, as well as markers of biological effect from exposure to crude oil/other oil spill exposures, such as hepatic injury, endocrine and immunological disruption, and markers of inflammation. Since most samples will have been collected after exposure ended, they will be useful primarily for measuring persistent or emerging effects.

\section{Statistical analyses}

Here, we present descriptive statistics (counts/proportions) of the full cohort, results from cross-sectional analyses based on survey 2 data, and preliminary results from comparisons of prospective health encounter data for categories of respiratory, neurological and dermal conditions based on three digit ICD-9 codes for active-duty members. All analyses were carried out using SAS V.9.3. ${ }^{41}$

In the current cross-sectional analyses, we used the survey data to evaluate associations between crude oil exposure and acute symptoms, some of which have been reported in previous oil spill studies (respiratory, neurobehavioural and dermal), ${ }^{6-19} 21$ and others less commonly characterised (eg, nausea/vomiting, abdominal pain, diarrhoea) ${ }^{811} 13-1542$ or not previously reported (eg, constipation, burning/painful urination, chest pain and sudden heartbeat changes). We restricted analyses to responders who completed survey 2, which collected data on these symptoms. We created a binary variable (ever vs never) for each health effect. Some responders reported multiple deployments; since this was a small number $(\mathrm{n}=292 ; 5 \%$ of survey takers), we limited the current analyses to data from first deployments.

We developed an oil exposure index (OEI) for semiquantitatively assessing crude oil exposure that incorporated responders' duration of oil spill response ( $<30$ days; $\geq 30$ days), timing of response relative to the oil well capping on 15 July 2010 (pre; post) and self-reported crude oil exposure (ever/never). Ever exposure to crude oil was based on providing a positive response for query of inhalation, ingestion, skin contact or submersion exposure to crude oil or oily water. We combined response duration, period of response and self-reported oil exposure into a three-level (none, low/medium, high) OEI.

To investigate associations between the OEI and acute symptoms, we calculated prevalence ratios (PR) and 95\% CIs using adjusted $\log$ binomial regression because of the non-rarity of many of the outcomes being examined. ${ }^{43}$ We evaluated age, gender, smoking, sleep, dispersant exposure and engine exhaust exposure as potential confounders. Potential confounders that changed estimates of association more than $10 \%$ were retained in final models, as well as age in all models and smoking in models for respiratory symptoms.

In the current prospective analyses, we used three-digit ICD-9 coded health encounter data for active-duty members to calculate incidence of select conditions and categories of conditions in the first approximately $21 / 2$ years after the DWH oil spill (through 31 December 2012). Follow-up for responders began on the deployment end date and for non-responders began on the median of all responder deployment end dates. Follow-up ended at the first encounter of a particular health condition/category, when a member departed the Coast Guard, or at the end of the follow-up period, 31 December 2012. Cases were restricted to those without evidence of a health encounter for the condition(s), queried prespill, from 1 October 2007 to the start of their follow-up. We present conditions most frequently reported in the literature as being associated with oil spill exposures (respiratory, neurological and dermal). We calculated incidence rates for responders and non-responders, as well as for oil exposed and non-oil-exposed responders, based on person-time follow-up, comparing by adjusted Poisson regression analyses to generate relative risks (RR) and 95\% CIs. In this analysis, oil exposure was based on reporting exposure during deployment to crude oil/oily water in either survey 1 or 2 . 


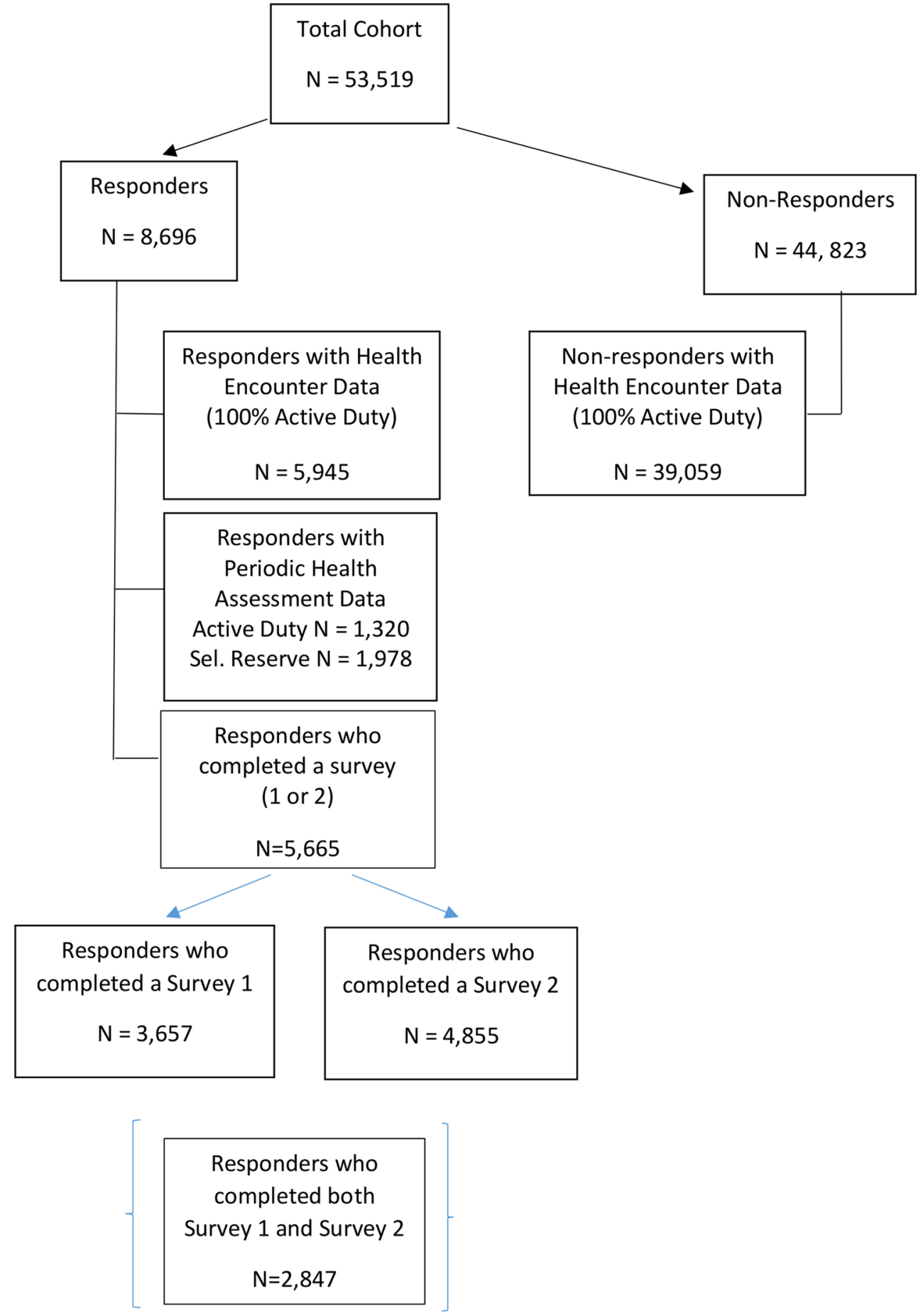

Figure 1 Flow chart of study population. Some of these categories are not mutually exclusive and may add up to more than their group's total.

\section{RESULTS}

The full cohort comprised all Coast Guard personnel who were either active-duty or in the Selected Reserve at any time between 20 April and 17 December $2010(\mathrm{n}=53519)$. A flow chart (figure 1) presents the various subgroups included in this study, which include 8696 Coast Guard DWH oil spill responders and 44823 non-responders. Table 1 presents frequencies of general characteristics for both groups, as well as frequencies by responders who completed a survey and those who did not. The responder population was slightly older and had more formal education on average than the non-responder population, while gender and racial distributions were similar. DWH responders included 5964 (68.6\%) active-duty Coast Guard personnel and 2732 (31.4\%) Selected Reserve personnel; as expected, these proportions differed for non-responders $(87.6 \%$ and $12.4 \%$, respectively). Of the 8696 responders, 5665 (65\%) completed a survey. General characteristics were similar between survey takers and non-survey takers, except that survey takers were slightly older, had a higher median length of deployment, were more likely to be reservists and to have started their deployment after the July 15 well capping. Over $26 \%$ of responders who completed a survey $(n=1494)$ reported sleeping an average of less than 6 hours per night and 18.9\% $(n=1068)$ smoked during their deployment. PPE use was common, with 4099 (72.4\%) 
Table 1 Baseline characteristics of DWH Oil Spill Coast Guard responders and non-responders

\begin{tabular}{|c|c|c|c|c|c|c|c|c|}
\hline \multirow[b]{2}{*}{ Characteristics } & \multicolumn{2}{|c|}{ Non-responders $(n=44823)$} & \multicolumn{2}{|c|}{ Responders $(\mathrm{n}=8696)$} & \multicolumn{2}{|c|}{$\begin{array}{l}\text { Responders who } \\
\text { completed a survey } \\
(n=5665)\end{array}$} & \multicolumn{2}{|c|}{$\begin{array}{l}\text { Responders who did } \\
\text { not complete a survey } \\
(\mathrm{n}=3031)\end{array}$} \\
\hline & $\mathrm{N}$ & $\%$ & $\mathrm{~N}$ & $\%$ & $\mathrm{~N}$ & $\%$ & $\mathrm{~N}$ & $\%$ \\
\hline Less than 25 years old & 12569 & 28.0 & 1658 & 19.1 & 986 & 17.4 & 672 & 22.2 \\
\hline 25-34 years old & 19197 & 42.8 & 3888 & 44.7 & 2489 & 43.9 & 1399 & 46.2 \\
\hline \multicolumn{9}{|l|}{ Gender } \\
\hline Male & 38290 & 85.4 & 7452 & 85.7 & 4809 & 84.9 & 2643 & 87.2 \\
\hline Female & 6533 & 14.6 & 1244 & 14.3 & 856 & 15.1 & 388 & 12.8 \\
\hline \multicolumn{9}{|l|}{ Ethnic group } \\
\hline White & 34495 & 77.0 & 6678 & 76.8 & 4324 & 76.3 & 2354 & 77.7 \\
\hline \multicolumn{9}{|l|}{ Employee class } \\
\hline Active duty & 39260 & 87.6 & 5964 & 68.6 & 3492 & 61.6 & 2472 & 81.6 \\
\hline Selected Reserve & 5563 & 12.4 & 2732 & 31.4 & 2173 & 38.4 & 559 & 18.4 \\
\hline \multicolumn{9}{|l|}{ Employee type } \\
\hline Enlisted & 36037 & 80.4 & 6467 & 74.4 & 4172 & 73.6 & 2295 & 75.7 \\
\hline Officer & 7627 & 17.0 & 2200 & 25.3 & 1474 & 26.0 & 726 & 24.0 \\
\hline Other (cadet/unknown) & 1159 & 2.6 & 29 & 0.3 & 19 & 0.3 & 10 & 0.3 \\
\hline \multicolumn{9}{|l|}{ Educational attainment } \\
\hline Less than high school graduate & 176 & 0.4 & 42 & 0.5 & 30 & 0.5 & 12 & 0.4 \\
\hline High school graduate or equivalent & 30378 & 67.8 & 5096 & 58.6 & 3208 & 56.6 & 1888 & 62.3 \\
\hline $3-5$ & & & 53 & 0.6 & 24 & 0.4 & 29 & 1.0 \\
\hline Median duration of DWH deployment (days) & & & 39.0 & & 48.0 & & 31.0 & \\
\hline \multicolumn{9}{|l|}{ Timing of DWH deployment† } \\
\hline Pre-July 15 capping of well & & & 6171 & 71.0 & 3882 & 68.5 & 2289 & 75.5 \\
\hline July 15 and after & & & 2400 & 27.6 & 1783 & 31.5 & 617 & 20.4 \\
\hline Missing & & & 125 & 1.4 & 0 & 0.0 & 125 & 4.1 \\
\hline \multicolumn{9}{|c|}{$\begin{array}{l}\text { Time between end of DWH deployment and taking } \\
\text { survey (days) } \ddagger\end{array}$} \\
\hline Survey 1 median & & & & & 1.0 & & - & - \\
\hline Survey 2 median§ & & & & & 153.0 & & - & - \\
\hline \multicolumn{9}{|l|}{ Average hours of sleep per night $\neq$} \\
\hline$<6$ & & & & & 1494 & 26.4 & - & - \\
\hline $6-<8$ & & & & & 3593 & 63.4 & - & - \\
\hline $8+$ & & & & & 578 & 10.2 & - & - \\
\hline \multicolumn{9}{|l|}{ Smoked during deploymentł } \\
\hline Yes & & & & & 1068 & 18.9 & - & - \\
\hline No & & & & & 4597 & 81.2 & - & - \\
\hline Use of any oil exposure-reducing PPE & & & & & 4099 & 72.4 & - & - \\
\hline
\end{tabular}


of responders reporting any use of oil exposure reducing PPE (including safety glasses, safety boots, protective headgear, gloves, Tyvek suits, waders and/or respirators). Of the 5665 who completed a survey, 4855 completed survey 2 . The median time between end of deployment and completion of survey 1 was 1 day. The median time for completing survey 2 (which was launched over 4 months after survey 1) was 153 days. Baseline characteristics were similar between those who completed survey 2 and those who completed only survey 1 (data not shown).

Additional characteristics of the members of the cohort who completed a survey are presented in online supplementary tables 1-3. Frequencies for responders' missions as well as a categorisation by likelihood of exposure to crude oil are presented in online supplementary table 1 . The two most reported missions were administrative support $(\mathrm{n}=2064)$ and incident command support/command post $(n=1685)$, both of which we categorised as not likely exposed to crude oil. The most commonly reported missions with a high likelihood of exposure to crude oil were booming/skimming operations $(n=1497)$, spill clean-up/decontamination $(n=1128)$ and safety/environmental health $(n=970)$. The frequencies of crude oil, oil dispersant and exhaust exposures, from survey $2(\mathrm{n}=4855)$, are presented in online supplementary table 2. Crude oil exposure was reported by $54.6 \%$ of these responders. Approximately half reported exposure to crude oil via inhalation, 3.3\% via ingestion, 34.9\% via direct skin contact and $17.7 \%$ via submersion of a body part in crude oil (they could report multiple routes of exposure). Oil dispersant exposure was reported by $40.4 \%$, including $22.0 \%$ who reported personally handling, applying or coming in contact with oil dispersants. As expected, there was appreciable overlap between crude oil exposure and contact with oil dispersants, with $91.1 \%$ of responders who reported dispersant exposure also reporting crude oil exposure (data not shown). Exhaust exposure was reported by $75.3 \%$ of responders. The frequencies of health effects reported in surveys 1 and 2 are presented in online supplementary table 3 . The survey(s) from which these health effects are derived is/are indicated in the table. The two most commonly reported symptoms were fatigue as a general symptom $(n=2814 ; 58.0 \%)$ and headaches $(n=1891 ; 39.0 \%)$.

PRs and 95\% CIs estimating the associations between acute health effects and crude oil exposure, as measured by the OEI, are presented in table 2 . There were statistically significant elevated PRs, which increased with exposure (low/medium vs none, and high vs none) for all three respiratory symptoms: coughing ( $\mathrm{PRs}=1.62,1.78)$, shortness of breath $(\mathrm{PRs}=1.78$, $2.30)$ and wheezing $(P R s=2.09,2.32)$. While all tests for trend were $<0.01$, for coughing there was a suggestion of a threshold effect. Two of the neurological symptoms, headaches $(\mathrm{PRs}=1.33,1.46)$ and light-headedness/dizziness (PRs $=1.74$, 1.96), showed possible dose-response relationships, although the similar magnitudes of the PRs for each symptom were also suggestive of a possible threshold effect. For skin rash/itching, while test for trend was $<0.01$, PRs were similarly elevated in both the low/medium $(\mathrm{PR}=1.91)$ and high $(\mathrm{PR}=1.87)$ categories of exposure. For gastrointestinal symptoms, there were increasing PRs with increasing exposure categories for diarrhoea $(\mathrm{PRs}=1.40,1.76$; $\mathrm{p}$ trend $<0.01)$ and stomach pain $(\mathrm{PRs}=1.41$, 1.67; p trend $<0.01$ ); for nausea/vomiting the PR was statistically significant only in the high exposure category $(\mathrm{PR}=1.48)$. The PR for the high exposure category in relation to the genitourinary symptom, burning/painful urination, was significantly elevated, with evidence of an exposure-response trend $(\mathrm{PR}=2.89$; $\mathrm{p}$ trend=0.02); however, the number of cases was small. Although there was an indication of increased prevalence for the cardiovascular symptom, sudden heartbeat changes, in the highest exposure category, it was not statistically significant $(\mathrm{PR}=1.50 ; 95 \% \mathrm{CI} 0.85$ to $2.66 ; \mathrm{p}$ trend $=0.17)$. Results for general categories of these symptoms, for example, any respiratory health effect, any neurological health effect, and so on, showed similar patterns of association as the individual symptoms in those categories. PRs and 95\%CIs for health effects associated with each individual component of the OEI are presented in online supplementary table 4. In general, there were increasing PRs with longer deployment, precapping timing of response and ever reporting oil exposure for many of the health effects measured.

Table 3 presents RRs and 95\% CIs for health outcomes, comparing incidence between active-duty responders with non-responders, and oil-exposed responders with non-oil-exposed responders, in the first approximately $21 / 2$ years after the DWH oil spill. Estimates were similar between active-duty responders and non-responders, with the exception of dermal conditions being slightly more elevated in responders than non-responders ( $R R=1.09$; 95\% CI 1.02 to 1.18). Among active-duty responders who completed a survey, those reporting any exposure to crude oil had elevated risks for chronic respiratory conditions $(\mathrm{RR}=1.32 ; 95 \% \mathrm{CI} 1.09$ to 1.58$)$, including asthma $(\mathrm{RR}=1.83 ; 95 \% \mathrm{CI} 1.05$ to 3.19$)$, and dermal conditions $(\mathrm{RR}=1.21 ; 95 \% \mathrm{CI} 1.01$ to 1.44$)$. Elevated RRs were also found for chronic obstructive pulmonary disease $(\mathrm{RR}=1.36$; 95\% CI 0.97 to 1.89$)$ and headaches/migraines $(\mathrm{RR}=1.35 ; 95 \% \mathrm{CI} 0.95$ to 1.92 ), with estimates approaching statistical significance.

\section{DISCUSSION}

The DWH Oil Spill Coast Guard Cohort study is a large, prospective study that has been established to evaluate both acute and long-term human health effects associated with oil spill exposures. Exposures of interest include crude oil via various routes — inhalation, ingestion, skin contact, submersion of body parts - as well as oil dispersants, engine exhaust, high temperatures, sun, ergonomic stress and psychological stress. The study has both prospective and cross-sectional components and will be able to investigate health effects that have been less commonly characterised or not previously reported, while confirming others previously reported in the literature. It is well positioned to prospectively assess long-term health outcomes among oil spill responders using comprehensive, administratively collected, objective healthcare data available on a large population of both responders and non-responders with equal access to healthcare, both prespill and postspill. For all active-duty members of the cohort, these objective healthcare data are continually collected, ICD-9-coded health encounter and pharmacy, laboratory and radiology data dating back to 2007. Linkage with future years' health encounter data will enable additional follow-up. For 23.8\% of the Selected Reserve cohort members, healthcare data consist of annual Periodic Health Assessments, dating back to 2009. Survey data available from over $60 \%$ of responders allow investigation of acute symptoms and injuries experienced at the time of the spill. Stored serum samples for cohort members are available for future measurement/analysis of markers of exposure, such as albumin adducts, and markers of biological effect from exposure to crude oil/other oil spill exposures, such as hepatic injury, endocrine and immunological disruption, and markers of inflammation.

Here, we have described the cohort and presented preliminary cross-sectional and prospective analyses of association between oil spill exposures and selected health effects. The demographics 
Table 2 Prevalence ratios (PRs) and 95\% Cls estimating the associations between acute health effects* and crude oil exposure, using the oil exposure index (OEI)

\begin{tabular}{|c|c|c|c|c|c|c|}
\hline Health effect & OEI & $\mathrm{N}_{\text {outcome }}$ & Prevalence & PR & $95 \% \mathrm{Cl}$ & p Trend \\
\hline \multicolumn{7}{|l|}{ Respiratoryt } \\
\hline \multirow[t]{3}{*}{ Any respiratory health effect $(n=1018)$} & None & 261 & 0.118 & 1.00 & & \\
\hline & Low/Medium & 339 & 0.271 & 1.62 & 1.39 to 1.89 & \\
\hline & High & 418 & 0.301 & 1.78 & 1.53 to 2.07 & $<0.01$ \\
\hline \multirow[t]{3}{*}{ Coughing $(n=942)$} & None & 241 & 0.109 & 1.00 & & \\
\hline & Low/Medium & 315 & 0.249 & 1.62 & 1.38 to 1.90 & \\
\hline & High & 386 & 0.278 & 1.78 & 1.52 to 2.08 & $<0.01$ \\
\hline \multirow[t]{3}{*}{ Shortness of breath $(n=265)$} & None & 53 & 0.024 & 1.00 & & \\
\hline & Low/Medium & 87 & 0.069 & 1.78 & 1.25 to 2.52 & \\
\hline & High & 125 & 0.090 & 2.30 & 1.65 to 3.21 & $<0.01$ \\
\hline \multirow[t]{3}{*}{ Wheezing ( $n=173$ ) } & None & 32 & 0.015 & 1.00 & & \\
\hline & Low/Medium & 32 & 0.025 & 2.09 & 1.34 to 3.25 & \\
\hline & High & 80 & 0.058 & 2.32 & 1.51 to 3.56 & $<0.01$ \\
\hline \multicolumn{7}{|l|}{ Neurologicalł } \\
\hline \multirow[t]{3}{*}{ Any neurological health effect $(n=2090)$} & None & 657 & 0.298 & 1.00 & & \\
\hline & Low/Medium & 635 & 0.503 & 1.31 & 1.20 to 1.44 & \\
\hline & High & 798 & 0.575 & 1.43 & 1.31 to 1.57 & $<0.01$ \\
\hline \multirow[t]{3}{*}{ Headaches $(n=1891)$} & None & 580 & 0.263 & 1.00 & & \\
\hline & Low/Medium & 579 & 0.458 & 1.33 & 1.20 to 1.47 & \\
\hline & High & 732 & 0.527 & 1.46 & 1.32 to 1.62 & $<0.01$ \\
\hline \multirow[t]{3}{*}{ Light-headedness/Dizziness ( $n=643$ ) } & None & 132 & 0.060 & 1.00 & & \\
\hline & Low/Medium & 225 & 0.178 & 1.74 & 1.40 to 2.18 & \\
\hline & High & 286 & 0.206 & 1.96 & 1.58 to 2.45 & $<0.01$ \\
\hline \multirow[t]{3}{*}{ Difficulty concentrating ( $\mathrm{n}=468)$} & None & 159 & 0.072 & 1.00 & & \\
\hline & Low/Medium & 130 & 0.103 & 0.97 & 0.76 to 1.24 & \\
\hline & High & 179 & 0.129 & 1.11 & 0.88 to 1.41 & 0.30 \\
\hline \multirow[t]{3}{*}{ Numbness or tingling sensations $(n=229)$} & None & 57 & 0.026 & 1.00 & & \\
\hline & Low/Medium & 71 & 0.056 & 1.14 & 0.78 to 1.66 & 0.20 \\
\hline & High & 101 & 0.073 & 1.26 & 0.88 to 1.82 & \\
\hline \multirow[t]{3}{*}{ Blurred/Double vision $(n=218)$} & None & 71 & 0.032 & 1.00 & & \\
\hline & Low/Medium & 30 & 0.024 & 0.87 & 0.59 to 1.27 & \\
\hline & High & 90 & 0.065 & 1.17 & 0.81 to 1.67 & 0.26 \\
\hline \multirow[t]{3}{*}{ Memory loss/Confusion ( $n=127)$} & None & 34 & 0.015 & 1.00 & & \\
\hline & Low/Medium & 44 & 0.035 & 1.60 & 0.93 to 2.76 & \\
\hline & High & 49 & 0.035 & 1.24 & 0.76 to 2.05 & \\
\hline \multirow[t]{3}{*}{ Tremors $(n=28)$} & None & 10 & 0.005 & 1.00 & & \\
\hline & Low/Medium & 5 & 0.004 & 0.31 & 0.10 to 1.01 & \\
\hline & High & 13 & 0.009 & 0.62 & 0.23 to 1.64 & 0.60 \\
\hline \multicolumn{7}{|l|}{ Dermalł } \\
\hline \multirow[t]{3}{*}{ Skin rash or itching $(n=536)$} & None & 103 & 0.047 & 1.00 & & \\
\hline & Low/Medium & 198 & 0.157 & 1.91 & 1.49 to 2.45 & \\
\hline & High & 235 & 0.169 & 1.87 & 1.45 to 2.40 & $<0.01$ \\
\hline \multicolumn{7}{|l|}{ Gastrointestinal‡ } \\
\hline \multirow[t]{3}{*}{ Any gastrointestinal health effect $(n=928)$} & None & 262 & 0.119 & 1.00 & & \\
\hline & Low/Medium & 284 & 0.225 & 1.28 & 1.08 to 1.51 & \\
\hline & High & 382 & 0.275 & 1.45 & 1.23 to 1.71 & $<0.01$ \\
\hline Diarrhoea $(n=622)$ & None & 151 & 0.069 & 1.00 & & \\
\hline & Low/Medium & 190 & 0.150 & 1.40 & 1.13 to 1.75 & \\
\hline & High & 281 & 0.202 & 1.76 & 1.42 to 2.17 & $<0.01$ \\
\hline Stomach pain $(n=454)$ & None & 112 & 0.051 & 1.00 & & \\
\hline & Low/Medium & 142 & 0.112 & 1.41 & 1.08 to 1.83 & $<0.01$ \\
\hline & High & 200 & 0.144 & 1.67 & 1.29 to 2.16 & \\
\hline Constipation $(n=325)$ & None & 99 & 0.045 & 1.00 & & \\
\hline & Low/Medium & 94 & 0.074 & 1.12 & 0.82 to 1.51 & \\
\hline & High & 132 & 0.095 & 1.28 & 0.95 to 1.72 & 0.09 \\
\hline
\end{tabular}




\begin{tabular}{|c|c|c|c|c|c|c|}
\hline Health effect & OEI & $\mathrm{N}_{\text {outcome }}$ & Prevalence & PR & $95 \% \mathrm{Cl}$ & p Trend \\
\hline \multirow[t]{3}{*}{ Nausea or vomiting $(n=300)$} & None & 72 & 0.033 & 1.00 & & \\
\hline & Low/Medium & 101 & 0.080 & 1.34 & 0.97 to 1.86 & \\
\hline & High & 127 & 0.091 & 1.48 & 1.07 to 2.04 & 0.02 \\
\hline \multicolumn{7}{|l|}{ Genitourinary $\ddagger$} \\
\hline \multirow[t]{3}{*}{ Burning or painful urination $(n=35)$} & None & 6 & 0.003 & 1.00 & & \\
\hline & Low/Medium & 9 & 0.007 & 1.49 & 0.48 to 4.56 & \\
\hline & High & 20 & 0.014 & 2.89 & 1.03 to 8.11 & 0.02 \\
\hline \multicolumn{7}{|l|}{ Cardiovascular $¥$} \\
\hline \multirow[t]{3}{*}{ Any cardiovascular health effect $(n=167)$} & None & 51 & 0.023 & 1.00 & & \\
\hline & Low/Medium & 44 & 0.035 & 0.91 & 0.58 to 1.41 & \\
\hline & High & 72 & 0.052 & 1.21 & 0.80 to 1.84 & 0.24 \\
\hline \multirow[t]{3}{*}{ Chest pain $(n=108)$} & None & 37 & 0.017 & 1.00 & & \\
\hline & Low/Medium & 24 & 0.019 & 0.64 & 0.36 to 1.13 & \\
\hline & High & 47 & 0.034 & 1.05 & 0.63 to 1.74 & 0.56 \\
\hline \multirow[t]{3}{*}{ Sudden heartbeat changes $(n=96)$} & None & 25 & 0.011 & 1.00 & & \\
\hline & Low/Medium & 29 & 0.023 & 1.30 & 0.72 to 2.34 & \\
\hline & High & 42 & 0.030 & 1.50 & 0.85 to 2.66 & 0.17 \\
\hline
\end{tabular}

${ }^{*}$ Acute health effects shown had at least five unexposed cases.

†Adjusted for age, exhaust exposure during deployment and smoking during deployment. $\ddagger$ Adjusted for age, dispersant exposure during deployment and exhaust exposure during deployment.Counts of responders by exposure level: none ( $N=2204)$; low/medium (N=1263); high ( $N=1388)$.

Bold typeface indicates statistical significance.

Table 3 Incidence of health conditions* + among active-duty USCG members, 2010-2012

\begin{tabular}{|c|c|c|c|c|c|c|c|}
\hline \multirow[b]{2}{*}{ Category } & \multicolumn{3}{|c|}{ Responder $(\mathrm{N}=5964)$} & \multicolumn{3}{|c|}{ Non-responder $(\mathrm{N}=39260)$} & \multirow[b]{2}{*}{ RR§ ๆ 95\% Cl } \\
\hline & Count & P-Y & IR & Count & P-Y & IR & \\
\hline Acute respiratory conditions (ICD-9:460-466) & 891 & 12366 & 72.05 & 5773 & 77923 & 74.09 & 0.98 (0.91 to 1.05$)$ \\
\hline Asthma (ICD-9:493) & 92 & 13433 & 6.85 & 560 & 85199 & 6.57 & 1.03 (0.82 to 1.28$)$ \\
\hline COPD (ICD-9:490-496) & 217 & 13265 & 16.36 & 1445 & 84150 & 17.17 & 0.94 (0.82 to 1.09$)$ \\
\hline Dermal conditions (ICD-9:690-692, 694, 701, 702, 709) & 871 & 12496 & 69.70 & 5025 & 79706 & 63.04 & 1.09 (1.02 to 1.18$)$ \\
\hline Category & \multicolumn{3}{|c|}{ Oil ever** $(\mathrm{N}=1908)$} & \multicolumn{3}{|c|}{ Oil Never** $(\mathrm{N}=1584)$} & \\
\hline Acute respiratory conditions (ICD-9:460-466) & 304 & 3972 & 76.54 & 233 & 3275 & 71.14 & 1.07 (0.91 to 1.27 ) \\
\hline $\begin{array}{l}\text { Chronic respiratory conditions (ICD-9:471-474,476- } \\
478,490-496,506,508)\end{array}$ & 289 & 4007 & 72.12 & 184 & 3357 & 54.81 & 1.32 (1.09 to 1.58$)$ \\
\hline Headaches and migraines (ICD-9:339, 346) & 79 & 4270 & 18.50 & 53 & 3509 & 15.10 & 1.35 (0.95 to 1.92$)$ \\
\hline $\begin{array}{l}\text { Neurological conditions, excluding headaches/migraines } \\
(\text { ICD-9:337, 341, 345, 348, 349) }\end{array}$ & 16 & 4340 & 3.69 & 9 & 3564 & 2.53 & 1.48 (0.66 to 3.36$)$ \\
\hline Dermal conditions (ICD-9:690-692, 694, 701, 702, 709) & 305 & 4002 & 76.21 & 211 & 3331 & 63.35 & $1.21(1.01$ to 1.44 \\
\hline $\begin{array}{l}\text { *Responders' follow-up period begins on the deployment end } \\
\text { tExcludes medical encounters that occurred after a participant } \\
\text { †IR: incidence rate based on searching health encounter data d } \\
\text { per } 1000 \text { person years. } \\
\text { §In responder/non-responder analysis, rate ratio was adjusted } \\
\text { gender for headaches and migraines. } \\
\text { IIIn oil ever/never analysis, rate ratio was adjusted for age and } \\
\text { neurological and dermal conditions. } \\
\text { **Ever versus never exposed to oil as reported in surveys } 1 \text { and } \\
\text { Bold typeface indicates statistical significance. } \\
\text { COPD, chronic obstructive pulmonary disease; ICD, Internationa }\end{array}$ & $\begin{array}{l}\text { date. Non- } \\
\text { exited the } \\
\text { lating back } \\
\text { for age for } \\
\text { smoking } f \\
\text { d 2. Bold ir }\end{array}$ & $\begin{array}{l}\text { ponders' fo } \\
\text { CG. } \\
\text { October } 2 \\
\text { piratory, as } \\
\text { espiratory, } \\
\text { ates statist }\end{array}$ & $\begin{array}{l}\text { Ip period } \\
\text { d excludi } \\
\text { COPD, n } \\
\text { significan }\end{array}$ & $\begin{array}{l}\text { is on the } \\
\text { ny cases } \mathrm{i} \\
\text { ogical an } \\
\text { age and g }\end{array}$ & $\begin{array}{l}\text { n of all res } \\
\text { ed prior to } \\
\text { al conditi } \\
\text { for heada }\end{array}$ & er follon & $\begin{array}{l}\text { Expressed as incidence } \\
\text { adjusted for age and } \\
\text { and age only for }\end{array}$ \\
\hline
\end{tabular}


of the DWH responders are similar to those of non-responders, with the exception that responders tended to be slightly older, had more formal education and consisted of more reservists. This finding is not unexpected, since Coast Guard personnel in the youngest age group (eg, <25 years) were more likely involved in training and not available/qualified for disaster response work. Additionally, a large proportion of reservists often participate in disaster responses. The mean duration of deployment for responders who completed a survey was similar to the typical 60-day deployment most Selected Reserve members would have carried out; this was 20 days on average more than the duration of deployment for non-survey takers. Reasons for this difference are unclear. Responders who completed a survey were more likely than those who did not complete a survey to start their deployment postcapping. This is likely due at least in part to the surveys not being available to responders until a few months after the start of the oil spill.

The current cross-sectional analyses provide preliminary estimates of associations between crude oil exposure and acute symptoms. We found associations between exposure to crude oil, using the OEI, for coughing, shortness of breath, wheezing, headaches, light-headedness/dizziness, skin rash/itching, diarrhoea, stomach pain, nausea/vomiting, and burning or painful urination. For some of these, shortness of breath, wheezing, light-headedness/dizziness, diarrhoea, stomach pain and burning/ painful urination, there was indication of an exposure-response relationship, while there appeared to be a threshold effect for the others. Our results confirm prior findings of positive associations among individuals exposed to oil spills, including those more commonly reported - respiratory, ${ }^{6-16}$ neurological $^{6-8} 11141517-19$ and dermal acute symptoms, ${ }^{7421}$; those less commonly reported - nausea, ${ }^{8} 11141520$ stomach pain ${ }^{6}$ and diarrhoea $^{42}$; and those, to our knowledge, not previously reported - genitourinary. The non-significantly elevated PR that we observed for sudden heartbeat changes was intriguing, since a prior study reported heart palpitations associated with 2 days or more versus 1 day of oil spill clean-up work. ${ }^{6}$ Sudden heartbeat changes, as assessed in our study, is non-specific, as it could indicate either an increase or decrease in heart rate. Two recent studies exposing large, pelagic fish to crude oil retrieved from the DWH oil spill reported an increase in atrial arrhythmias, indicating that crude oil can interfere with the signalling mechanisms of the heart in these vertebrate animals, ${ }^{45}$ although its cardiac effects in humans remain unclear.

In our cross-sectional analyses, there were many positive associations. While these symptoms may, indeed, have been affected by oil spill clean-up exposures, some findings, particularly those with a threshold effect rather than an exposure-response, may alternatively be attributable to the condition of medically unexplained physical symptoms (MUPS). MUPS are common in survivors of disasters and are more prevalent in those affected by disasters compared with the general population. ${ }^{46}$ This phenomenon, however, may be less likely for health effects showing an exposure-response relationship.

Analyses of the prospective health encounter data indicate that health effects associated with the oil spill response may be more apparent when comparing exposed responders with non-exposed responders than when comparing responders with non-responders. This is likely due in part to the fact that responders were a heterogeneous group, many of whom were not exposed to oil, and it may also possibly stem from the healthy worker/responder effect. However, even responders not exposed to oil may have been exposed to other spill-related stressors. Nonetheless, these are preliminary comparisons and should be interpreted with caution, particularly those for which numbers are small. Systematic analysis of this rich data source, accounting for spill-related exposures and controlling for relevant confounders, will be required to accurately identify adverse health effects associated with participation in the spill response and with specific exposures.

There are several limitations that should be considered for both the overall study and the results presented here. Assessment of exposure to crude oil and other agents relies on self-report, which could be subject to recall bias, and given the cross-sectional study design, we cannot determine the temporality of exposure and acute health effects. Although exposure to oil dispersants was queried in survey 2, the questions about these exposures did not ask specifically about Corexit 9527A and 9500 exposure; thus, our future analyses of the effects of these exposures must consider this non-specificity. However, most responders are unlikely to have known which dispersants they were being exposed to. Another limitation is that there was incomplete participation in the surveys by responders; however, we found no major differences between survey takers and non-survey takers (table 1), with the exception that survey takers had a higher median length of deployment, were more likely to be reservists and to have started their deployment after the July 15 well capping. Since this is a healthy study population, given their employment in the military and young age, health encounters for some conditions relevant to oil exposure may have low counts. However, more cases will accrue over time, and the study has the unique ability to evaluate potential long-term health effects of these oil spill responders using health encounter data. Smoking data are not consistently available for the entire cohort; thus, adjustment of relevant health outcomes by smoking may not be possible in some prospective analyses. Strengths of the study include a large study population with equal access to healthcare and availability of continually collected, objective health data both prior to and post the DWH spill. For responders who took a survey, recall of their deployment is expected to be good, given the relatively short lag time between completion of deployment and completing a survey. The metrics of crude oil exposure we applied in the analyses presented here are based on more than fact of participation in the oil spill response or the duration of oil spill clean-up work, which have characterised much of the literature to date. Future analyses from this cohort will be based on even more specific oil exposure metrics, considering route of exposure, for example, since there are questionnaire data for inhalation, ingestion and dermal exposures. The study also has the ability to evaluate associations between oil spill clean-up work and health effects not previously reported in the literature, but that are biologically plausible, for example, constipation, burning/painful urination and sudden heartbeat changes. Another strength of the study is that Coast Guard personnel are generally healthy and less likely than the general population to have pre-existing conditions that could bias observed associations. Moreover, in our prospective analyses here, we excluded prevalent cases dating back to 2007 , thereby mitigating possible bias from pre-existing conditions.

Future efforts will include more detailed analyses based on the survey data, incorporating information on routes of exposure, missions, use of specific oil and dispersant exposure-reducing PPE, and factor analysis to identify any exposure groupings. Health effects associated with other exposures - oil dispersants, engine exhaust, high temperatures, sleep deprivation, ergonomic and psychological stress, as well as combinations of these with crude oil exposure - will also require in-depth analysis. Both the Military Health System Data Repository health 
encounter data for active-duty members and the Periodic Health Assessment data for reservists will be systematically evaluated, focusing on specific case definitions, adjusting for pre-existing conditions and careful consideration of potential confounders. Laboratory data from the Military Health System Data Repository and the Periodic Health Assessment will also be leveraged; pharmaceutical data can further refine case definitions. Additionally, banked, serial serum samples will allow investigation of both markers of exposure and of biological effect among responders. Following cohort members while they remain in the Coast Guard will enable us to evaluate long-term health effects of oil spill response work.

Most studies of the human health consequences of oil spills have been cross-sectional, ${ }^{47}$ focusing primarily on acute physical and psychological effects, and have relied on proxies of exposure to crude oil. Longitudinal studies are important for evaluating the long-term health effects associated with oil spills. Because of the magnitude of the DWH oil spill, the likelihood of future spills and the very limited health effects research conducted to date, long-term studies of oil spill responders are urgently needed. The DWH Oil Spill Coast Guard Cohort study will play a critical role in filling this knowledge gap.

Acknowledgements The authors would like to thank the US Coast Guard for providing the data for this study.

Contributors JR (PI) conceived, designed and executed the study and wrote the manuscript. LSE (Co-PI) designed and executed the study, worked closely with the $\mathrm{PI}$ in all aspects. EGS (co-PI) assisted with making data available from the US Coast Guard and helped execute the study. MA obtained, managed and analysed the data. LaW provided expertise/advice on Coast Guard personnel exposures. JB provided expertise/advice on medical encounter data. LiW assisted with interpretation of the results and editing. $\mathrm{KC}$ and DJ provided key data management and data analysis. RHF assisted with survey design. All coauthors provided assistance in interpreting results and editing the manuscript.

Funding This study was supported by a National Institutes of Health grant (R01ES020874).

Disclaimer The views expressed here are those of the authors and do not necessarily reflect the official views of the Uniformed Services University of the Health Sciences, the Department of Defense, the United States Coast Guard, The Department of Homeland Security, or the Centers for Disease Control and Prevention.

Competing interests None declared.

Ethics approval Uniformed Services University.

Provenance and peer review Not commissioned; externally peer reviewed.

(c) Article author(s) (or their employer(s) unless otherwise stated in the text of the article) 2018. All rights reserved. No commercial use is permitted unless otherwise expressly granted.

\section{REFERENCES}

1 Graham BRW, Beinecke F, Boesch D, et al. In: NCotBD H, OSaO D, Ulmer F deep water: the gulf oil disaster and the future of offshore drilling, 2011.

2 Federal On Scene Coordinator. On Scene Coordinator Report: Deewpater Horizon Oil Spill, 2011.

3 NIOSH. Evaluating the Health Impacts of the Gulf of Mexico Oil spill testimory before the Committee on Health, Education, Labor and Pensions: john Howard, MD, Director NIOSH. Washington, D. C: Department of Health and Human Services, 2010.

4 Aguilera F, Méndez J, Pásaro E, et al. Review on the effects of exposure to spilled oils on human health. J Appl Toxicol 2010;30:n/a-301.

5 D'Andrea MA, Reddy GK. Crude oil spill exposure and human health risks56(10):1029-41. 10.97/. J Occup Environ MedJOM 2014;56:1029-41.

$6 \mathrm{Ha} \mathrm{M}$, Kwon H, Cheong HK, et al. Urinary metabolites before and after cleanup and subjective symptoms in volunteer participants in cleanup of the Hebei Spirit oil spill. Sci Total Environ 2012:429:167-73.

$7 \mathrm{Na} J \mathrm{JU}, \mathrm{Sim} \mathrm{MS}$, Jo IJ, et al. The duration of acute health problems in people involved with the cleanup operation of the Hebei Spirit oil spill. Mar Pollut Bull 2012;64:1246-51.

8 Peres LC, Trapido E, Rung AL, et al. The Deepwater Horizon Oil spill and Physical Health among Adult women in Southern Louisiana: the women and their Children's Health (WaTCH) Study. Environ Health Perspect 2016;124:1208-13.
9 Zock JP, Rodríguez-Trigo G, Rodríguez-Rodríguez E, et al. Persistent respiratory symptoms in clean-up workers 5 years after the Prestige oil spill. Occup Environ Med 2012;69:508-13.

10 Zock JP, Rodríguez-Trigo G, Rodríguez-Rodríguez E, et al. Evaluation of the persistence of functional and biological respiratory health effects in clean-up workers byears after the prestige oil spill. Environ Int 2014;62:72-7.

11 Carrasco JM, Lope V, Pérez-Gómez B, et al. Association between health information, use of protective devices and occurrence of acute health problems in the Prestige oil spill clean-up in Asturias and Cantabria (Spain): a cross-sectional study. BMC Public Health 2006:6:1.

12 Meo SA, Al-Drees AM, Meo IM, et al. Lung function in subjects exposed to crude oil spill into sea water. Mar Pollut Bull 2008;56:88-94.

13 Meo SA, Al-Drees AM, Rasheed S, et al. Effect of duration of exposure to polluted air environment on lung function in subjects exposed to crude oil spill into sea water. Int J Occup Med Environ Health 2009;22:35-41.

14 Schvoerer C, Gourier-Frery C, Ledrans M, et al. Epidemiologic study on short-term health alterations in people participating in the cleanup of places contaminated by Erika oil (in French). 2000. htttp://wwwinvssantefr/publications/erika3/rapmaree_ distpdf

15 Suárez B, Lope V, Pérez-Gómez B, et al. Acute health problems among subjects involved in the cleanup operation following the Prestige oil spill in Asturias and Cantabria (Spain). Environ Res 2005;99:413-24.

16 Kim YM, Park JH, Choi K, et al. Burden of disease attributable to the Hebei Spirit oil spill in Taean, Korea. BMJ Open 2013;3:e003334.

17 Campbell DCD, Crum J, Foster K, et al. Initial effects of the grounding of the tanker Braer on health in Shetland. BMJ 1993;307:1251-5.

18 Lyons RA, Temple JM, Evans D, et al. Acute health effects of the Sea Empress oil spill. $J$ Epidemiol Community Health 1999;53:306-10.

19 Morita A, Kusaka Y, Deguchi Y, et al. Acute health problems among the people engaged in the cleanup of the Nakhodka oil spill. Environ Res 1999;81:185-94.

20 Meo SA, Al-Drees AM, Rasheed S, et al. Health complaints among subjects involved in oil cleanup operations during oil spillage from a greek tanker "Tasman Spirit". Int $\lrcorner$ Occup Med Environ Health 2009;22:143-8.

21 Baars BJ. The wreckage of the oil tanker 'Erika'--human health risk assessment of beach cleaning, sunbathing and swimming. Toxicol Lett 2002;128:55-68.

22 Noh SR, Cheong HK, Ha M, et al. Oxidative stress biomarkers in long-term participants in clean-up work after the Hebei Spirit oil spill. Sci Total Environ 2015;515516:515207-51614.

23 Hildur K, Templado C, Zock JP, et al. Follow-Up genotoxic study: chromosome damage two and six years after exposure to the Prestige Oil spill. PLoS One 2015;10:e0132413

24 Laffon B, Aguilera F, Ríos-Vázquez J, et al. Endocrine and immunological parameters in individuals involved in Prestige spill cleanup tasks seven years after the exposure. Environ Int 2013:59:103-11.

25 Laffon B, Aguilera F, Ríos-Vázquez J, et al. Follow-up study of genotoxic effects in individuals exposed to oil from the tanker Prestige, seven years after the accident. Mutat Res Genet Toxicol Environ Mutagen 2014;760:10-16.

26 Laffon B, Fraga-Iriso R, Pérez-Cadahía B, et al. Genotoxicity associated to exposure to Prestige oil during autopsies and cleaning of oil-contaminated birds. Food Chem Toxicol 2006;44:1714-23

27 Pérez-Cadahía B, Laffon B, Pásaro E, et al. Genetic damage induced by accidental environmental pollutants. ScientificWorldJournal 2006:6:1221-37.

28 Pérez-Cadahía B, Laffon B, Valdiglesias V, et al. Cytogenetic effects induced by Prestige oil on human populations: the role of polymorphisms in genes involved in metabolism and DNA repair. Mutat Res 2008:653:117-23.

29 Pérez-Cadahía B, Lafuente A, Cabaleiro T, et al. Initial study on the effects of Prestige oil on human health. Environ Int 2007:33:176-85.

30 Palinkas LA, Petterson IS, Russell J, et al. Community patterns of psychiatric disorders after the Exxon Valdez oil spill. Am J Psychiatry 1993;150:1517-23.

31 Choi KH, Lim MH, Ha M, et al. Psychological vulnerability of residents of Communities affected by the Hebei Spirit Oil spill. Disaster Med Public Health Prep 2016;10:51-8

32 Lee $\mathrm{CH}$, Kang YA, Chang KJ, et al. [Acute health effects of the Hebei oil spill on the residents of Taean, Korea]. J Prev Med Public Health 2010;43:166-73.

33 Sabucedo JM, Arce C, Senra C, et al. Symptomatic profile and health-related quality of life of persons affected by the Prestige catastrophe. Disasters 2010;34:809-20.

$34 \mathrm{Sim} \mathrm{MS}$, Jo IJ, Song HG. Acute health problems related to the operation mounted to clean the Hebei Spirit oil spill in Taean, Korea. Mar Pollut Bull 2010;60:51-7.

35 National Commission on the BP Deepwater Horizon Oil Spill and Offshore Drilling. The use of surface and Subsea Dispersants during the BP Deepwater Horizon Oil spill (Draft), 2010

36 Agency for Toxic Substances and Disease Registry (ATSDR). Oil spill dispersant (COREXIT囚 EC9500A and EC9527A) Information for Health Professionals, 2010

37 National Institute for Occupational Safety and Health (NIOSH). Deepwater Horizon Response Chemical Dispersant Research. Atlanta, GA: CDC NIOSH, 2012. https:// www.cdc.gov/niosh/topics/oilspillresponse/chemDispersant.html (accessed 06 Jan 2017). 
38 Rusiecki JA, Thomas DL, Chen L, et al. Disaster-related exposures and health effects among US Coast Guard responders to Hurricanes Katrina and Rita: a cross-sectional study. J Occup Environ Med 2014;56:820-33.

39 Bergan T, Thomas D, Schwartz E, et al. Sleep deprivation and adverse health effects in United States Coast Guard responders to Hurricanes Katrina and Rita. Sleep Health 2015;1:268-74.

40 Perdue CL, Eick-Cost AA, Rubertone MV. A brief description of the operation of the DoD serum repository. Mil Med 2015;180(10 Suppl):10-12.

41 SAS Institute. The SAS system for Windows, 2012. [published Online First: 9.3].

42 Ordinioha B, Sawyer W. Acute health effects of a crude oil spill in a rural community in Bayelsa State, Nigeria. Niger J Med 2010;19:140-4.
43 Barros AJ, Hirakata VN. Alternatives for logistic regression in cross-sectional studies: an empirical comparison of models that directly estimate the prevalence ratio. BMC Med Res Methodol 2003;3:21.

44 Brette F, Machado B, Cros C, et al. Crude oil impairs cardiac excitation-contraction coupling in fish. Science 2014;343:772-6.

45 Incardona JP, Gardner LD, Linbo TL, et al. Deepwater Horizon crude oil impacts the developing hearts of large predatory pelagic fish. Proc Natl Acad Sci U S A 2014;111:E1510-E1518.

46 van den Berg B, Grievink L, Yzermans J, et al. Medically unexplained physical symptoms in the aftermath of disasters. Epidemiol Rev 2005:27:92-106.

47 Laffon B, Pásaro E, Valdiglesias V. Effects of exposure to oil spills on human health: updated review. J Toxicol Environ Health B Crit Rev 2016;19(3-4):105-28. 